\title{
АНАЛИЗ МЕТОДОВ ДИАГНОСТИКИ ПАЦИЕНТОВ С КЛИНОВИДНЫМИ ДЕФЕКТАМИ ЗУБОВ И СПОСОБОВ ЛЕЧЕНИЯ ПРИ ПОРАЖЕНИИ ДЕНТИНА
}

\section{ANALYSIS OF DIAGNOSTIC METHODS FOR PATIENTS WITH WEDGE-SHAPED DENTAL DEFECTS AND TREATMENT METHODS FOR DENTIN LESIONS}

T. Simonyan

Summary. This article is devoted to research on the diagnosis of wedgeshaped defects. It is revealed as a natural fact that the intensity of the glow of a wedge-shaped defect that has a surface stage of development increases, while with the aggravation of the defect to a deep degree, the indicator noticeably decreases. The intensity of the glow is minimal for deep lesions of the tooth tissue with a wedge-shaped defect. The use of modern x-ray diagnostics with a computed tomography Protocol is highly informative for individuals whose wedge-shaped defect has reached a late stage of development.

Keywords: wedge-shaped defect, diagnosis of patients.

\author{
Симонян Татьяна Владимировна \\ К.м.н., преподаватель, Пятигорский медико- \\ фармацевтический институт - филиал \\ Волгоградского государственного медицинского \\ университета \\ shpitzbaum@mail.ru
}

Аннотация. Данная статья посвящается исследованиям диагностики клиновидных дефектов. Выявлен как закономерный тот факт, что интенсивность свечения клиновидного дефекта, имеющего поверхностную стадию развития нарастает, тогда как с усугублением дефекта до глубокой степени показатель заметно падает. Интенсивность свечения является минимальной для глубоких поражений ткани зуба клиновидным дефектом. Использование современной рентгенодиагностики с протоколом компьютерной томограммы высоко информативно для лиц, у которых клиновидный дефект достиг поздней стадии развития.

Ключевые слова: клиновидный дефект, диагностика пациентов.
B настоящее время диагностической и терапевтической проблемой для стоматологов является поражение твердых тканей зуба некариозными патологическими изменениями. Распространение указанного деструктивного процесса приближается по частоте в популяции только к кариозным разрушениям зубов. Из-за патологии дентин и эмаль убывают в объёме, а жевание как функция становится неполноценным. Не менее важно, что это приводит к образованию косметических проблем [1]. Нужно понимать, что начальные проявления кариеса и клиновидных дефектов довольно схожи, и выражаются сначала в появлении шероховатости на поверхности. Поначалу убыль зубных тканей минимальна. В итоге некариозные заболевания сложно диагностируются, и это осложняет лечебно-профилактические мероприятия.

Современные стоматологи используют небольшое разнообразие методик и диагностических средств, а лидерских позиций не оставляют традиционно сложившиеся вопросы о клинике путем обследования пациента, когда собираются анамнестические данные, проводится осмотр, делается температурное тестирование, пробуется зондом полость а эмаль зуба подвергается витальной окраске. Но методики, несмотря на тщательность и скру- пулезность реализации, не являются гарантией точной дифференциальной диагностики клиновидного дефекта, что особенно справедливо в ранней стадии патологии. Данный аспект фокусирует внимание стоматологов на потребности достоверно диагностировать и дифференцировать клиновидные дефекты.

В перспективе решение проблемы ожидается за счет распространения устройств для люминесцентной спектроскопии. Сегодня подобная аппаратура уже позволяет эффективно выполнять дифференциальную диагностику гинекологических, онкологических, офтальмологических патологий [6].

Некариозные и кариозные поражения твердых тканей зуба являются настолько распространенными и сложно различимы в процессе диагностики, что исследовательская деятельность практически всё XX столетие была нацелена на процесс флуоресценции зубов, что привело к настоящему дню к использованию доступного и информативного инструмента для диагностики [9].

Формирование клиновидного дефекта начинается на границе, где стыкуется эмалевое покрытие и цемент. Ткани разрушаются преимущественно на поверхности, 
а стенка дефекта содержит слои дентина и цемента незначительно, а превалирует эмаль зубов.

На сегодня специалисты могут перечислить ряд наиболее вероятных теорий о причинах формирования клиновидных дефектов: генетическая предрасположенность, механические повреждения, соматические причины. При этом невозможно сказать, какая из этих причин заболевания более популярна. Российская литература имеет следующую классификацию стадий развития данного дефекта: начальная стадия, дефекты развиты поверхностно, степень поражения достигла среднего уровня или перешла в глубокую стадию.

Исследования демонстрируют, что в зоне образования клиновидных дефектов образуются существенные нарушения структур твердых зубных тканей [6]. Для некариозных поражений, включая клиновидные дефекты, на начальных этапах типично такое явление, как демирализация зубной эмали. Это явление происходит под воздействием соединения с кислой реакцией, способные окислить и разрушить твёрдую ткань поражённого патологическим процессом зуба. Однако эмаль подвергается частичному растворению из-за способности кристаллического гидроксилапатита кальция переходить в растворенное состояние при условии, что кислотность не достигает высоких показателей (pH) [3].

Начальная стадия заболевания проявляется тем, что эмалевое покрытие и цементный конгломерат разделяются щелью, которая начинает нарастать, когда в пораженном участке активно убывает дентин и цемент. Эмаль по характеру приобретает вид нависающего края. Если клиновидные дефекты прогрессируют, связующие дентин и эмаль связи разрушаются, а нависшая эмаль постепенно отделяется от дентина и легко скалывается. В результате здоровые ткани и клиновидный дефект явно отграничиваются друг от друга. Патологический процесс распространяется в объеме и охватывает интактные ткани.

Если клиновидный дефект достигает глубокой стадии, ткань дентина минерализуется значительно, из-за чего канальцы дентина облитерируются. Это характерно для поверхности дентина, утратившего эмаль, тогда как по режущему краю патологических изменений не отмечается. Применяя метод комбинационного рассеяния, рассматривалась ткань дентина, чтобы по молекулярной структуре определить степень и характер некариозных дефектов, поразивших ткани зуба в области шейке [10].

В частности, удалось зафиксировать изменения в дентине: повышенная минерализация пронизывает слой до 10 мкм, где превалируют фосфаты, тогда как карбонатзамещенные кристаллы гидроксилапатита кальция пони- жены в количестве. Подобные ткани более интенсивно кристаллизированы, из-за чего деструкция частично настигает волокна коллагена [1].

Диагностика пациентов с клиновидными эффектами дефектами зубов по методу ЛИФ проводится, опираясь на раскрытый наукой механизм свечения твердый зубной ткани, уже поражённой патологическим процессом или оставшейся интактной. За рубежом научные исследования акцентируют, что [5] реакция твердых тканей зуба отличается по характеру, так как может иметь предпосылки органического и неорганического генеза. Эмаль показывает свечение, интенсивность которого связана с анатомией зуба, его местом на челюсти. Результаты исследований доказывают непосредственную корреляцию свечения эмали с прочими тканями зуба, такими как дентин и ДЭГ, что и становится причиной сильного расхождения флуоресценции. Но свечение достигает высокого уровня интенсивности при наличии ДЭГ со структурным разрезом на многих уровнях процесса, а эмаль показывает минимальную интенсивность свечения. Исследования показали, что флуоресценция в случае ДЭГ даёт слабый сигнал, когда как дентин или эмалевое покрытие, прилежащие к дефекту и имеющие раковины, светятся интенсивно.

Область шейки зуба является тем сектором, где показанный эмалью без повреждений спектр флуоресценции захватывает показатели ДЭГ и дентина, выше областей на режущих краях или в экваториальной зоне.

Клиновидный дефект на стадии поверхностного поражения характеризует убыль эмалевого покрытия, когда поверхность эмали уже начинает повреждаться щелевидными образованиями. Дефект развивается неглубоко, порядка 0,2 мм, располагаясь практически на границе стыка покрытия и цементного агломерата. Зубная эмаль истончается, а трещины обосновывают более интенсивное свечение в зоне клиновидного дефекта, который еще развился ещё только как поверхностный, тогда как интактная эмаль проявляет более низкий уровень свечения.

Истончение эмалевого слоя в зоне патологических изменений позволяют излучению проникнуть глубже, возбудить в тканях флуоресцентный процесс, из-за чего дентин и ДЭГ подключаются к спектральному срезу эмалевой флуоресценции.

Клиновидный дефект, зашедший на среднюю стадию, поражает ткани зуба, локализуется на глубине 0,2-0,3 мм. Проникновение клиновидного дефекта до глубоких слоев является причиной типичных поражений дентина. Если дефект достиг средней или глубокой стадии развития, свечение по интенсивности падает, что обусловлено несколькими факторами: 
1. Патология, зашедшая до тяжёлой стадии или ставшей причиной среднего дефекта, уже начала разрушать ДЭГ, а покрытие зубов эмалью разрушилось, ткани, прилежащие к дефекту, начали изменяться, так как дентин трансформируется и проявляет нетипичные участкам дентина состав минералов и химическую реакцию [3].

Перенасыщенный минеральными соединениями слой дентина утрачивает в количественной характеристике карбонатзамещенные кристаллы гидроксилапатита кальция, тогда как коллагеновые волокна разрушаются.

В твердых тканях зуба флуоресценция обусловлена наличием собственных агентов, присутствующих в коллагене и являющихся примесью и кристаллизованного гидроксилапатита кальция, из-за чего с разрушением коллагена и изменением порога минерализации клиновидный дефект демонстрирует падение флуоресцентного спектра по интенсивности, когда болезнь доходит до уровня средней стадии или глубже.

2. Дефект имеет форму полости, стенки которой начинают обретать нетипичные здоровым тканям оптические свойства, их плотность возрастает, что мешает потоку флуоресцентного излучения проникнуть в глубину тканевой структуры зуба. Это является предпосылкой снижения свечения по уровню интенсивности.

Первоначально клиновидный дефект практически незаметен, так как ткани убывают медленно и незаметно, а диагностика сложна и является в большей мере исключением, чем закономерностью. Разрушающаяся эмаль показывает более яркое свечение, если сопоставить с участками не затронутого патологическим процессом эмалевого покрытия.

Повсеместное распространение компьютерных томографов как инновационной техники на стоматологических учреждениях России позволяет использовать современную аппаратуру для диагностики клиновидных дефектов. Диагност выполняет послойный спиральный снимок зуба. Сегодня рентгенодиагностика в формате компьютерной томографии проникла в отечественную стоматологию и показала востребованность в качестве диагностического инструмента при исследовании патологии ротовой полости, обследуя и выявляя поражения пародонта и периодонта, а также зубов кариозными и некариозными процессами [9].

Вышесказанное позволяет отметить, что методика диагностики пациентов с клиновидными дефектами зубной эмали является перспективным направлением, актуальным и востребованным для сегодняшней стоматологии. Однако сегодня метод ещё не является безупречным в плане ранней диагностики, так как на практике сложно отграничить интактную зубную эмаль от поверхности зуба, уже подвергшейся начальной или поверхностной стадии клиновидных дефектов. Важным лимитирующим фактором являются лучевая нагрузка, так как флуоресцентный поток имеет определённую кратность применения для диагностики. Указанную методику рационально использовать в стоматологических отделениях, где диагностируются клиновидные дефекты, развившиеся до средней или глубокой стадии в процессе профилактического обследования ротовой полости.

\section{ЛИТЕРАТУРА}

1. Боровский, Е. В. Реминерализация твердых тканей зуба/Е.В. Боровский, П. А. Леус // Стоматология. — 1977. — № 2.— C. 77-84.

2. Гилева, 0.С. Повышенная чувствительность зубов: методические рекомендации. - Пермь, 2009. - $30 \mathrm{c}$.

3. Окушко, В. Р. Клиновидные и другие гладкие дефекты тканей зуба /В.Р. Окушко // Новое в стоматологии. — 2003. -№ 8 - С. $16-19$.

4. Рубежова, Н. В. Особенности клинического течения и лечения больныхсэрозиями, клиновиднымидефектами и повышеннойстираемостью зубов: дисс.... канд. мед. наук. - М., 2003.

5. Максимовская, Л. Н. Использование десенситайзера двойного действия для лечения повышенной чувствительности твердыхтканей зуба // Маэстро стоматологии.-2002.— № 2(7).- С. 80-81.

6. Посохова, В.Ф. « Нанофлюор» - биоактивный фторирующий лак нового тысячелетия / В. Ф. Посохова, В. П. Чуев, Л. Л. Гапочки-на и [др.]// Институт стоматологии. - 2011.—№ 1.- С. 52.

7. Семченко, И. М. Эффективность лечебно-профилактических мероприятий при клиновидных дефектах зубов / И. М. Семченко //Белорусский мед. журнал. - 2003.— № 3.— С. 24-28.

8. Федоров, Ю. А. Особенности диагностики и новые принципы лечения некариозных поражений зубов/Ю.А. Федоров, В.А.

9. Дрожжина, П. М. Чернобыльская и др. // Новое в стоматологии. — 1996. — № 3.— C. 10-12.

10. Kolker J. L., Vargas M. A., Armstrong S. R. Effect of dentin desensitizing agents on dentin permeability // J. Dental Res. 2002. — Vol. 81.—P. 63.

11. G. Vanherle, B. Van Meerbek, M. Braem, P. Lambrechts. Clinicalaspects of Dentin Bonding Materials of International Simposium EURODISNEY, Paris March, 24-25, 1993.

(с Симонян Татьяна Владимировна ( shpitzbaum@mail.ru).

Журнал «Современная наука: актуальные проблемы теории и практики» 